\title{
Extended Oligoarticular Juvenile Idiopathic Arthritis
}

National Cancer Institute

\section{Source}

National Cancer Institute. Extended Oligoarticular Juvenile Idiopathic Arthritis. NCI

Thesaurus. Code C119041.

Oligoarticular juvenile idiopathic arthritis that eventually involves more than four separate joints. 